\title{
Depredación de coral vivo por peces en el Parque Nacional Natural Tayrona, Caribe colombiano
}

María Catalina Reyes-Nivia, Jaime Garzón-Ferreira \& Alberto Rodríguez-Ramírez

Instituto de Investigaciones Marinas y Costeras INVEMAR. A.A 1016 Santa Marta, Colombia. Fax: (+57)-5-4315761; catareyes@invemar.org.co; jgarzon@invemar.org.co; betorod@invemar.org.co

Este artículo se publicó en el Volumen 52, fascículo 4, correspondiente al mes de diciembre 2004. Por error de la imprenta la figura 1 presenta su imagen en tonalidades invertidas (negativo). Se adjunta la imagen impresa correctamente.
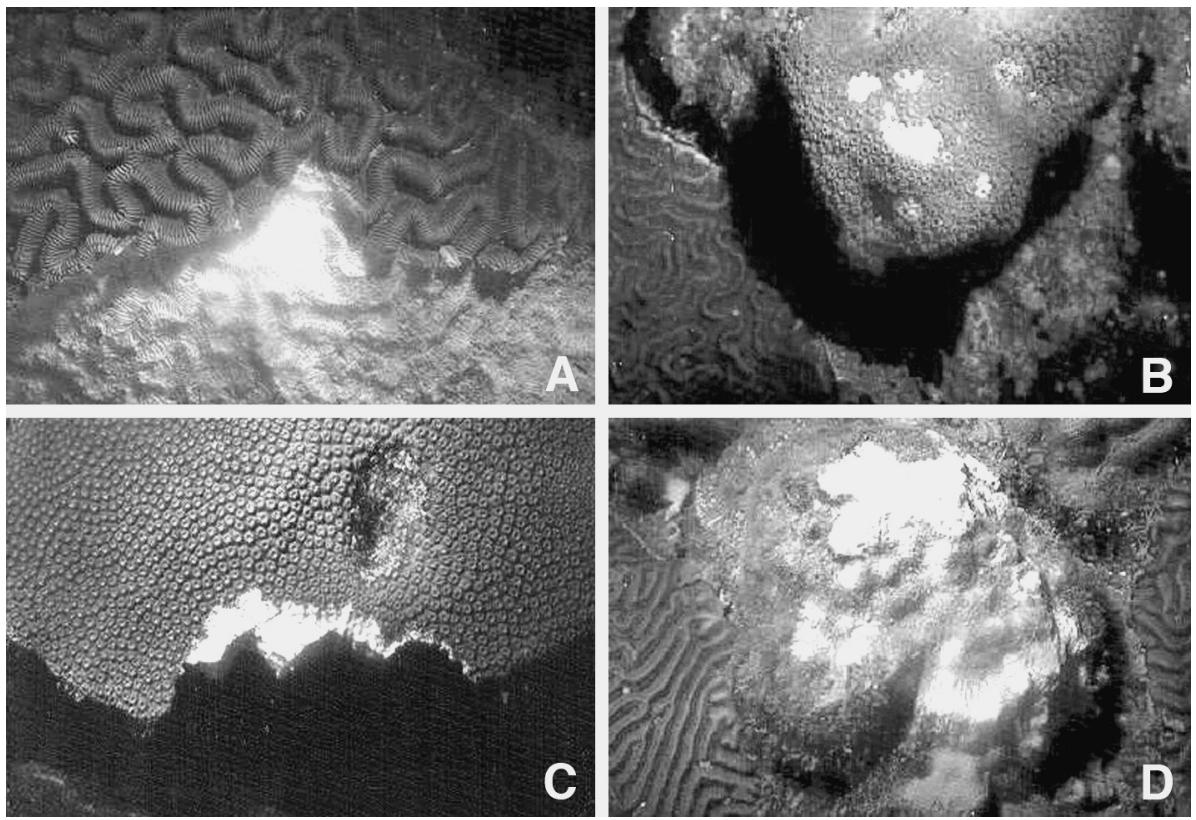

Fig. 1. Mordiscos individuales, característicos en las especies de corales depredadas por Sparisoma viride. A. Colpophyllia natans B. Montastraea annularis. C. M. faveolata. D. Porites astreoides (Fotos A y C por M. C. Reyes-Nivia y fotos B y D por A. Rodríguez-Ramírez).

Fig. 1. Typical individual bites of the coral species predated by Sparisoma viride. A. Colpophyllia natans B. Montastraea annularis. C. M. faveolata. D. Porites astreoides (Pictures A and C by M. C. Reyes-Nivia, $\mathrm{B}$ and $\mathrm{D}$ by A. Rodríguez-Ramírez). 